\title{
Entre o individual e o coletivo: a biografia como uma saída
}

ROSENTHAL, Gabriele. História de vida vivenciada e história de vida narrada: Gestalt e estrutura de autoapresentações biográficas. Tradução de Tomas da Costa. Porto Alegre: EdiPUCRS, 2017. $295 p$.

\section{Camila Ferreira Silva* Rodrigo de Macedo Lopes** (1)}

\section{Resumo}

Trata-se de resenha crítica da obra História de vida vivenciada e história de vida narrada: Gestalt e estrutura de autoapresentações biográficas da socióloga alemã Gabriele Rosenthal, traduzida e lançada no Brasil em 2017. O exercício intelectual empreendido pela autora ao situar as histórias de vida e as narrativas biográficas nos horizontes epistemológico, teórico, metodológico e também frente a debates consagrados no interior da Sociologia (tais como: indivíduo e sociedade ou objetividade e subjetividade) ganha aqui centralidade, com vistas a apontar o lugar de uma obra como esta no cenário das ciências sociais no Brasil.

Palavras-chave: Histórias de vida, Narrativas biográficas, Gestalt, Sociologia.

* Universidade Nova de Lisboa, Lisboa, Portugal.

** Universidade Federal do Rio Grande do Sul, Porto Alegre - RS, Brasil. 


\section{Between individuality and collectivity: the biography as a way out}

\section{Abstract}

This is a critical review of the work História de vida vivenciada e história de vida narrada: Gestalt e estrutura de autoapresentações biográficas by the German sociologist Gabriele Rosenthal, translated and released in Brazil in 2017. The focus is put on the intellectual endeavor undertaken by the author to locate life histories and biographical narratives within the epistemological, theoretical, methodological horizons, and also in the scope of sociological debates such as those involving individual and society or objectivity and subjectivity. In doing so, we aim at situating the work in the scenario of Brazilian social sciences.

Keywords: Life stories, Biographical narratives, Gestalt, Sociology.

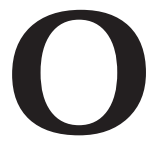

desenvolvimento da Sociologia enquanto disciplina científica coloca-nos hodiernamente diante de uma área do saber diversificada, heterogênea, complexa e multiparadigmática (Alexander, 1987). É, pois, dentro deste quadro que diferentes concepções de Sociologia, perspectivas epistemológicas, teóricas e metodológicas coexistem e disputam espaço e legitimidade no "jogo da ciência" (Bourdieu, 2008). Dentre as muitas disputas que marcam este campo, interessa-nos aqui saber qual o estatuto da singularidade na Sociologia - questão outrora já enfrentada por Brandão (2007), mas que aqui ganha o papel de antessala para a apresentação da obra de Gabriele Rosenthal.

De acordo com Gilberto Velho (2006, p. 4), “[a] preocupação e o lugar do indivíduo dentro das ciências sociais têm sido questão muitas vezes polêmica e sempre estimulante" e, longe de consenso na comunidade acadêmica, persistem debates em torno de uma espécie de desconfiança relativa a subjetividade, procedimentos indutivos, representatividade analítica e teórica, fiabilidade e rigor no âmbito de investigações que se 
valem, por exemplo, de estudos de casos, biografias ou histórias de vida. Segundo Brandão (2007, p. 3), essa desconfiança deve-se à força da herança positivista na Sociologia, bem como à confusão entre relevância estatística e relevância analítica e, neste contexto, à reificação do número (Becker, 1994), e ainda ao estatuto problemático que tem sido historicamente atribuído à singularidade no interior das ciências sociais (Touraine, 1982; Hamel, 1992).

As correlações, entretanto, entre as esferas individual e coletiva, que passaram a ganhar novo fôlego no debate sociológico na segunda metade do século XX, colocam-nos diante da compreensão de que a história do indivíduo é, também, uma especificação da história coletiva de seu grupo (Bourdieu, 1983) - o que pode ser traduzido com a seguinte frase, "O mundo me contém e me engole como um ponto, mas eu o contenho" (Bourdieu, 2011, p. 27). E é exatamente a partir deste entendimento que a "unidade indivisível da vida pessoal" (Simmel, 2006, p. 11) passa a figurar como um importante elemento nas pesquisas no âmbito das ciências sociais. Como este debate se relaciona, afinal, com o livro de Gabriele Rosenthal?

A tradução da obra História de vida vivenciada e história de vida narrada: Gestalt e estrutura de autoapresentações biográficas para o português, em 2017, insere-se, pois, no cenário de ampliação das discussões e pesquisas acerca das histórias de vida no cenário nacional ${ }^{1}$ - o que nos permite afirmar que a publicação deste livro em solo brasileiro é reveladora das referências que têm sido utilizadas para dar conta dos embates dos quais tratamos nos primeiros parágrafos deste texto -, de um lado, e no estreitamento de parcerias internacionais no terreno da Sociologia, aqui expresso pelo

\footnotetext{
${ }^{1}$ Alguns elementos expressam este cenário de ampliação, dentre os quais destacamos a realização e consolidação do Congresso Internacional sobre Pesquisa (Auto)biográfica (CIPA), desde 2004 (o qual, em 2018, realizar-se-á em São Paulo); a partir deste congresso, a criação da Associação Brasileira de Pesquisa (Auto)biográfica (BIOgraph) em 2008; o crescimento do número de grupos de pesquisa que trazem a pesquisa biográfica em seus nomes, em suas linhas de pesquisa e/ou nas suas palavras-chave (o que pode ser visualizado a partir de uma busca no Diretório dos Grupos de Pesquisa no Brasil do CNPq); e ainda a ampliação de produção científica, acompanhada de um alargamento do horizonte de áreas do conhecimento e das opções teóricas e metodológicas (Ramos et al., 2017).
} 
diálogo Brasil-Alemanha, de outro. Se levarmos em consideração, ainda, que a professora Gabriele Rosenthal, na oportunidade do lançamento desta obra no Brasil, em 2017, realizou uma série de conferências no Rio Grande do Sul, São Paulo e Rio de Janeiro, evidente se torna como esta questão das parcerias e dos diálogos foi sendo efetivada.

Para entendermos o impacto da obra de Rosenthal no debate sobre histórias de vida no Brasil, partamos, primeiramente, do exercício de situá-la no cenário acadêmico, especialmente com referência aos estudos biográficos. Gabriele Rosenthal é socióloga, doutora em Sociologia pela Universität Bielefeld, com livre-docência em Sociologia pela Universität Kassel, e atualmente atua como professora e pesquisadora no Centro de Métodos em Ciências Sociais da Universidade de Göttingen. Sua inserção internacional tem-se dado tanto pelo desenvolvimento de investigações e atuações como professora visitante, desde o final dos anos 1980, quanto por cargos de prestígio em instituições de pesquisa relacionadas aos estudos biográficos e à pesquisa qualitativa², desde a metade dos anos 1990, em países como: Alemanha, Estados Unidos, Israel, Inglaterra, Gana, Uganda, Brasil, entre outros. No âmbito de seu trabalho, Rosenthal é reconhecida pela sistematização correlacional da teoria da Gestalt, da sociologia do conhecimento e da sociologia figuracional de Norbert Elias, com vistas a elucidar a dialética que marca a relação entre experiência, memória e narrativa. Nesse sentido, a autora tem buscado introduzir na Sociologia o que denomina de método biográfico, o que faz ao trabalhar com a reconstrução de casos a partir de entrevistas narrativas biográficas.

Esta breve incursão pela trajetória da autora acaba por permitir-nos apontar qual o lugar que a obra aqui resenhada ocupa na sua produção mais ampla: o livro não busca realizar um apanhado de diferentes escolas teóricas e metodológicas sobre os estudos biográficos, tampouco ocupa-se

2Dentre eles destacamos o Presidente do comitê "Biography and Society" da Internacional Sociological Association (ISA), entre 2002 e 2010; o Presidente da seção Biographical Research na German Association of Sociology, entre 1999 e 2003; o membro do conselho editorial da The Narrative of Lives, editado por Ruthellen Josselson da Towson State University e por Amia Lieblich da The Hebrew University of Jerusalem, entre 1993 e 2000. 
de sintetizar os resultados das pesquisas de Rosenthal; seu objetivo consiste em, por outro lado, oferecer uma rica fundamentação para a sociologia interpretativa preocupada com a análise de narrativas biográficas.

O livro organiza-se em seis partes, a saber: "Introdução", onde a autora demonstra a definição do problema, situando historicamente o surgimento e a tônica da pesquisa biográfica e delineando para o leitor as bases de sua abordagem gestáltica; "Sobre o aspecto gestáltico da vivência", parte responsável por conectar as noções de manifestação das coisas e dos processos sociais à organização formal do agente e dos observadores; a terceira parte, "Sobre o aspecto gestáltico da recordação e da narrativa", ata as pontas entre memória e narrativa; enquanto "Sobre a Gestalt de histórias de vida narradas", quarta parte da obra, traz uma discussão em torno da construção de uma narrativa de vida (seus esquemas, a ordenação e as conexões); "O efeito terapêutico do relato biográfico" compõe a quinta parte e trata tanto da ambiguidade gestáltica da história de vida vivenciada (entre autonomia e possibilidades de invenção), quanto da suavidade do relato biográfico frente à terapia; por fim, a autora aborda as "Implicações metodológicas" na última parte da obra, dialogando com o leitor acerca da importância da escuta, da recordação cênica e ainda dos princípios de análise reconstrutiva de um caso.

A pesquisa do tipo biográfica é, pois, tomada à discussão a partir de perspectivas que ultrapassam a Sociologia e, ao promover este extravasamento da área, a autora nos permite acessar fundamentos de áreas como a Psicologia e a História com vistas a aprofundar debates relacionados às histórias de vida que atravessam diversos campos do saber, posto que diferentes pesquisadores têm se ocupado deles: é o caso, por exemplo, da relação entre indivíduo e sociedade, a qual ocupa certa centralidade nos escritos da autora.

Em função desta centralidade - a qual nos indica que este constitui um dos fios condutores da obra em questão -, este é o primeiro ponto ao qual nos debruçaremos mais detidamente. Rosenthal inicia sua obra enfrentando três árduos debates no âmbito das ciências sociais e da Sociologia, a saber: 
a questão dos modismos; o "dualismo" indivíduo-sociedade; e o "dualismo" objetividade-subjetividade. Seria a pesquisa biográfica somente mais um modismo teórico-metodológico? A resposta da autora para esta questão traz uma cuidadosa reconstrução do percurso de desenvolvimento da pesquisa biográfica no cenário internacional, no sentido de demonstrar não somente a preocupação de pesquisadores das mais diferentes áreas com as biografias, mas também de demarcar a relação entre os processos de modernização da sociedade e o lugar das biografias enquanto meios de estruturação social.

Neste sentido, Rosenthal parte do próprio conceito de biografia para enfrentar os outros dois debates. De modo que, de um lado, a autora sugere a utilização deste conceito como uma saída para o impasse do dualismo indivíduo-sociedade, posto que a biografia como formação social constitui concomitantemente a realidade social e os mundos de experiências e vivências dos indivíduos. $\mathrm{E}$, de outro, demonstra como, ainda com base na biografia, é possível observar os embates entre objetivo e subjetivo na pesquisa em ciências sociais, uma vez que a história de vida vivenciada é relegada ao objetivamente ocorrido, em uma espécie de processo de "purificação" de tudo que seja subjetivo, o que reforça a concepção de uma dualidade entre a história de vida vivenciada e a história de vida narrada.

As correlações entre história de vida vivenciada e história de vida narrada ganham, pois, espaço privilegiado neste livro - fato que se expressa mais obviamente pelo título da obra, mas igualmente pela retomada ao longo de todas as suas partes com vistas a demarcar suas imbricações aproximativas e diferenciadoras de forma dialética. Vale a pena, neste caso, trazer aqui as questões norteadoras que Gabriele Rosenthal enuncia como ponto de partida para suas reflexões, porquanto elas nos ajudam a vislumbrar os elos entre experiência e narração: "O que significa uma interpenetração entre acontecido, vivenciado e narrado? Sobre o que nos informa a história de vida narrada? Quais procedimentos metodológicos nos podem auxiliar na tarefa de compreender e explicar esse fenômeno social?" (p. 25). 
A teoria da Gestalt é aliada à Fenomenologia para o exercício que Gabriele Rosenthal compartilha com seus leitores no decorrer do livro: compreender a relação dialética entre vivenciar, recordar e narrar. Tal exercício é executado a partir da tríade diálogo com a literatura, exemplificação de casos e avanço no debate teórico-metodológico. Destacamos nomes como Fritz Schütze, Edmund Husserl, Edgar Rubin, Aron Gurwitsch, Max Wertheimer e Wolfgang Köhler com o intuito de demonstrar quem são os interlocutores de Rosenthal na sua combinação entre situar a literatura especializada e, com isso, captar dela sínteses significativas para o trabalho com histórias de vida. Alguns elementos deste movimento merecem relevo, nomeadamente as relações entre: noema e objeto; tema, campo e margem; percepção, organização, acomodação e consciência; além das relações entre formas temporais e formas espaciais e a experienciação do tempo.

Com o objetivo de ilustrar suas reflexões, faz-se mister apontar quão rica é esta obra. Rosenthal, ao transitar pelos pensadores supracitados, bem como pelos entendimentos que enumeramos acima, traz exemplos de relatos que acabam por auxiliar a visualização da operacionalização dos conceitos no nível da literatura especializada. Tais relatos, que são de fato trechos de narrativas biográficas, constituem banco de dados da própria autora - ou seja, de suas pesquisas realizadas nos mais diversos contextos de investigação e também de estudantes nos seus seminários - e também oriundos de exemplos já clássicos da Gestalt. Estes relatos, primeiramente, servem como fundamento empírico para as questões às quais Rosenthal se debruça em seu livro e, ulteriormente, colocam o leitor em contato com um dos produtos/dados de uma pesquisa com histórias de vida, com narrativas biográficas. Neste sentido, este compartilhamento com os leitores desencadeia um processo pedagógico com relação às questões teóricas e metodológicas que envolvem uma investigação deste tipo: como uma entrevista biográfica é realizada? Que implicações as bases da Gestalt trazem para a realização de uma pesquisa como esta? Como é realizada a análise das narrativas? São estes exemplos de questões que a autora não 
necessitou expor no início de seu livro, mas que ganham respostas pautadas no exercício de partilhar seus dados e seu olhar sobre eles.

Em que pesem as críticas que podem ser tecidas em torno dos usos abusivos da noção de biografia nas ciências humanas, sociais e na sociologia - dentre as quais destacamos: a tônica no individual e o avizinhamento com o individualismo; os limites da relação entre memória e materialidade nas autobiografias; e o segmentarismo subjetivista (Conde, 1993) - o presente livro assume um caráter elucidativo das bases da pesquisa com narrativas biográficas caras ao universo da investigação sociológica. A lucidez de Gabriele Rosenthal no que tange à articulação entre a vivência e a narração das histórias de vida reacende debates importantes em torno das relações entre passado e presente, indivíduo e sociedade, subjetivo e objetivo e, sobretudo, como tais relações se apresentam no cotidiano das investigações sociológicas. Ratifica-se a tônica atribuída à relação dialética entre experiência, recordação e narração ao longo desta obra, posto que esta é a chave para a superação de uma perspectiva puramente objetivista sobre as narrativas biográficas: com Rosenthal, compreende-se que as experiências naturalmente estão situadas no passado e, por isso, não podem se apresentar aos biografados no tempo presente (no momento de recordação e narração) da mesma maneira como foram vivenciadas; estas experiências "chegam" aos sujeitos na correlação entre o que se oferece no presente da narração e o que a pessoa quer dizer.

Gabriele Rosenthal, por meio deste livro, traz à tona questões pertinentes para a sociologia no Brasil, as quais, no entanto, não se circunscrevem somente a esta área do conhecimento. Há aqui um movimento mútuo entre a utilização de outros campos do saber no desenvolvimento das suas reflexões, de um lado, e uma contribuição que ultrapassa os limites da sociologia, de outro - o que nos leva a sublinhar a relevância da obra para os mais diversos públicos interessados pela temática das histórias de vida. Desse modo, Rosenthal contribui de forma ampla para o debate em torno do significado de uma ação social e da tematização de seu contexto de surgimento, por meio da ligação entre história individual e social. 
Camila Ferreira da Silva é Doutora em Ciências da Educação pela Universidade Nova de Lisboa (UNL), Portugal.

$\equiv$ ferreira.camilasilva@gmail.com

Rodrigo de Macedo Lopes é Doutorando em Sociologia da Universidade Federal do Rio Grande do Sul, Brasil.

$\equiv$ rlopes9@gmail.com

\section{Referências}

1. ALEXANDER, Jeffrey C. O novo movimento teórico. Revista Brasileira de Ciências Sociais, v. 2, n. 4, p. 2-28, jun. 1987.

2. BECKER, Howard S. Métodos de pesquisa em Ciências Sociais. São Paulo: Editora Hucitec, 1994.

3. BOURDIEU, Pierre. Questões de sociologia. Trad. Jeni Vaitsman. Rio de Janeiro: Marco Zero, 1983.

4. BOURDIEU, Pierre. Para uma sociologia da ciência. Lisboa: Edições 70, 2008.

5. BOURDIEU, Pierre. Razões práticas: sobre a teoria da ação. Campinas: Papirus Editora, 2011.

6. BRANDÃO, Ana Maria. Entre a vida vivida e a vida contada: a história de vida como material primário de investigação sociológica. Configurações, n. 3, p. 83106, 2007.

7. CONDE, Idalina. Problemas e virtudes na defesa da biografia. Sociologia. Problemas e práticas, n. 13, p. 39-57, 1993.

8. HAMEL, Jacques. On the status of singularity in Sociology. Current Sociology, v. 40, n. 1, p. 99-119, 1992.

9. RAMOS, Michel D. P.; OLIVEIRA, Rita de Cássia. M.; SANTOS, Maria Rita. Estado da arte da pesquisa (auto)biográfica: uma análise do portal de periódicos CAPES. Revista Brasileira de Pesquisa (Auto)Biográfica, Salvador, v. 2, n. 5, p. 449-69, maio/ago. 2017.

10. ROSENTHAL, Gabriele. História de vida vivenciada e história de vida narrada: Gestalt e estrutura de autoapresentações biográficas. Tradução de Tomas da Costa. Porto Alegre: EdiPUCRS, 2017.

11. SIMMEL. Georg. Questões fundamentais da sociologia: indivíduo e sociedade. Rio de Janeiro: Zahar, 2006.

12. TOURAINE, Alain. Pela Sociologia. Lisboa: D. Quixote, 1982.

13. VELHO, Gilberto. Ciências sociais e biografia individual. Estudos Históricos, Rio de Janeiro, n. 38, p. 3-9, jul./dez. 2006. 
Recebido: 25 abr. 2018

Aceito: 31 jul. 2018 